\title{
Wheat Yield Forecasting Based on Landsat NDVI and SAVI Time Series
}

\author{
Odunayo David Adeniyi, Andrea Szabó, János Tamás, Attila Nagy \\ University of Debrecen, Faculty of Agricultural and Food Sciences and Environmental \\ Management, Institute of Water and Environmental Management
}

\begin{abstract}
Due to increase demand of food grain in the world, assessment of yield before actual production is important in making policies and decisions in agricultural production system. For a large area, forecast models developed from vegetation indices derived from remote sensing satellite data possesses the potential to give quantitative and timely information on crops over large areas. Different vegetation indices are being made used for this purpose, however, their efficiency in estimating crop yield is needed to be certainly tested. In this study, wheat yield forecast was derived by regressing ground truthing yield data against time series of spatial vegetation indices for the 2013 to 2019 growing seasons. These spatial vegetation indices derived from Landsat 8 image data: Normalized Difference Vegetation Index (NDVI) and Soil Adjusted Vegetation Index (SAVI) were compared to evaluate the most appropriate index that performs better in forecasting wheat production at Karcag, Kunhegyes and Ecsegfalva settlements in Jász-Nagykun-Szolnok county, in the Northern Great Plain region of central Hungary. The best time for making wheat yield prediction with Landsat 8- SAVI and NDVI was found to be the beginning of ripening period $\left(160^{\text {th }}\right.$ day of the year) with higher correlation between the vegetation indices and the wheat yield. The validation results revealed that the model from SAVI provides more consistent and accurate forecasts yield compared to NDVI. The SAVI model forecast yield for the validation years, 2018 and 2019 were within $6.00 \%$ and $4.41 \%$ of the final reported values while that of NDVI model were within $8.31 \%$ and $6.27 \%$. Nash-Sutcliffe efficiency index is positive with $\mathrm{E}_{1}=0.99$ for the model from SAVI and for NDVI, $E_{1}=0.57$, which connote that the forecasting method developed and evaluated performs acceptable forecast efficiency.
\end{abstract}

Keywords: NDVI, EVI, Wheat yield forecasting, Landsat 8 


\section{Introduction}

In the world today, there has been increase in concern about food security and sustainable agricultural development of which a key component is the accurate estimation of supply and demand of major crops like wheat. Wheat is the third most grown cereal after maize and rice with a production of 3.07metric tons/ha globally (World Wheat Production, 2016). Regarding to the 2008 food crisis and also the challenges of feeding the growing population, global agriculture and yield monitoring initaitives is needed. Due to increase demand of food grain in the world, assessment of yield before actual production is important in making policies and decisions in agricultural production system. Also, estimation of crop yield and early crop yield forecasting has a significant importance for policy makers to make timely decisions in planning for exports. Also, since world trading prices of agricultural products depends largely on their seasonal production levels, crop yields under crop production is important for national and international agricultural agencies, government agencies, and other crop marketing agencies too to set prices based on expected yield and plan earlier transportation of the crops.

The use of remote sensing for biomass monitoring has its base from its close relation to the canopy Leaf Area Index (LAI) and Fraction of Absorbed Photosynthetically Active Radiation (fAPAR) (Baret and Guyot, 1991; Prince 1991). Baret and Guyot (1991) discussed the potentials of different vegetation indices using the normalized difference vegetation indices, soil adjusted vegetation indeices, perpendicular vegetation index, and transformed soil adjusted vegetation index and described the relation between the vegetation indices and the Leaf Area Index (LAI) and fraction of absorbed photosynthetic active radiation. Prince (1991) also developed a model of crop primary production relating to the amount of absorbed photosynthetically active radiation (APAR) to net production of which it was discussed that there is an approximately linear relationship between the absorbed photosynthetically active radiation (APAR) and the normalized difference vegetation index (NDVI). Because of this almost linear relation, vegetation indices can be used as an indirect measure of primary crop productivity. The relationship described here between vegetation indices and biomass/fAPAR helps us to estimate crop yield since yield of many crops is mainly determined by the photosynthetic activity of agricultural plants in certain periods prior to harvest (Benedetti and Rossini, 1993, Baret et al., 1989). 
The interest in using satellite remote sensed data today for crop monitoring and crop production forecasting has tremendously increased due to its potential to produce data synoptically, with much spatial coverage, potentially at the global scale. Moreover, remote sensing is capable of providing timely (and potentially real-time) and objective data on crop growth at relatively minimum cost. Remote sensed vegetation indices (VIs) such as Normalized Difference Vegetation Index (NDVI) in particular has been greatly utilized for agricultural mapping and monitoring. In the past, National Oceanic and Atmospheric Administration's (NOAA) Advanced Very High-Resolution Radiometer (AVHRR) have been data source since 1980's for large scale crop yield forecasting and monitoring (Tucker et al., 1985; Malingreau, 1986). Recently, remote sensing-based yield forecasting research has shifted to the National Aeronautics and Space Administration's (NASA) Moderate Resolution Imaging Spectroradiometer (MODIS) and other spatial resolution sensors. However, the spatial resolution of MODIS data is relatively low, with an available $250 \mathrm{~m}, 500 \mathrm{~m}$ and $1000 \mathrm{~m}$ (Bolton and Friedl, 2013). Cai and Sharma (2010) estimated crop yield of rice and wheat for IndusGanges River Basin with MODIS $250 \mathrm{~m}$ data. They pointed out inappropriate pixel size that affected accuracy. However, Liaqat et al., (2017) on the same area evaluated MODIS and Landsat multiband vegetation indices for wheat yield and discussed that vegetation indices (SAVI) derived from Landsat 8 satellite gives better estimation in the area. The Landsat 8 produces data with higher spatial resolution $(30 \mathrm{~m})$ and free availability (Woodcock et al., 2008). The higher the spatial resolution of a remote sensing data, the better its assistance in the identification of the low-resolution pixels. Studies on the relationship between crop yield and Landsat-derived vegetation indices are mostly bound to focus on individual fields (Liu et al., 2006; Lyle et al., 2013; Potgieter et al., 2014). Since Landsat derived vegetation indices have been proven to be one of the effective as tools for assessing vegetation condition, it is valid to use them to predict crop yield.

According to some field studies and airborne scanner experiments (e.g. Tucker, 1979; Tucker et al., 1980), green vegetation can be monitored by their spectral reflectance properties and combinations of the red and near-infrared reflecatnces (Vegetation indices). Deering (1978) proposed the Normalized Difference Vegetation Index which has become the most widely used for studying vegetation health and crop production. Moreover, minimizing the distribution of the effects on the relationships between vegetation spectral reflectance and crop yield, some researchers (like; Wu et al., 2007; Pena-Barragan et al., 2011; Dempewolf et al., 2014; Fu et al., 2014; Xie et al., 2015) refer to distance based vegetation indices such as Soil Adjusted 
Vegetation Index (SAVI). SAVI is applied in correcting Normalized Difference Vegetation Index (NDVI) for influencing of soil brightness in areas where vegetative cover is low.

Rembold et al., (2013) gave a comprehensive overview regarding biomass and yield prediction methods. many studies focused on the quantitative relation between satellite or airborne remote sensing data and crop yields and make use of two main methods of the general strategies (Ferencz et al., 2004). The first method is by incorporating satellite remote sensing data into existing or advanced plant physiology, crop growth models (such as in Reynolds et al., 2000; Patel et al., 2001; Richter et al., 2011; Vuolo et al., 2013). The second method of general strategy is using direct mathematical relationships between satellite remote sensing and crop yields; in some researches, models use only satellite remote sensing data with ground-truth reference (reported crop statistics) data for calibration while some improve the predictive power of remotely sensed indicators by adding meteorological and agronomical data into the models. (such as in Rudorff and Barista., 1991; Dempewolf et al., 2014). There other studies on Linear regression models relating vegetation indices to crop yield (Rasmussen, 1992; Groten, 1993; Maselli et al., 1992).

Nagy et al., (2018) regressing reported yield values of Wheat and maize yield against time series of 15 different peak-season MODIS-derived NDVI and showed that MODIS-NDVI could be used effectively to predict crop yields for Tisza river catchment area 6-8 weeks before harvest, and Bognára et al., (2017) also used time series of MODIS data to estimate and forecast the winter wheat yield of Hungary. This study will be using the same methodology but focusing on using vegetation indices derived from time series of Landsat 8 data to forecast winter wheat yield in Karcag, Ecsegfalva and Kunhegyes settlemets which are part of Jász-NagykunSzolnok county in Hungary. The independent variable will be vegetation indices (SAVI and NDVI) and an empirical regression model will be developed to estimate final wheat yield which is the dependent variable.

\section{Material}

\subsection{Study site}

The study area is focused on Karcag, Kunhegyes and Ecsegfalva settlements in Jász-NagykunSzolnok county, in the Northern Great Plain region of central Hungary. The region lies in Latitude $47^{\circ} \mathrm{N}$ and longitude $20^{\circ} \mathrm{E}$. This county has a humid continental climate with average precipitation of $495 \mathrm{~mm}$. Breeding of winter wheat is better in quality on fields of the Institutes 
for Agricultural Research and Educational Farm of the University of Debrecen, Research Institution of Karcag.

\subsection{Crop Statistical Data}

Crop data/ Ground truth data, the average wheat yield ( $\mathrm{t} / \mathrm{ha}$ ) of this area was obtained from the Research Institute of Karcag from 2013 to 2019. The data obtained were the identification of the farm, the year and the crop yield data.

\subsection{Landsat Data}

The time series Landsat 8 satellite images for the growing season 2013 to 2019 was downloaded from USGS website (http://earthexplorer.usgs.gov/). was used. There are 11 bands in Landsat 8. It also has operational land imager (OLI) and thermal infrared sensors (TIRS) with nine spectral bands and $30 \mathrm{~m}$ spatial resolution. True-colour image are produced when the bands 1 to 7 which have different wavelengths with red, green and blue sensors are combined together. Band 8 has $15 \mathrm{~m}$ resolution while the new band 9 which is ultra-blue is useful for cloud detection and for coast and aerosol studies. The band 10 and 11 are thermal bands which has their usefulness in providing more accurate surface temperature with $100 \mathrm{~m}$ resolution (Landsat science, 2013). However, the Band 4 (red) and 5 band (NIR) were used for further processing.

\section{Methods}

\subsection{Spectral vegetation indices}

ArcGIS 10.2 was used to calculate the vegetation indices from the processed images then what yield estimation were computed (Fig. 3). And figure () shows the flow chart of the methodology. Landsat Surface Reflectance-derived Normalized Difference Vegetation Index (NDVI), and Soil Adjusted Vegetation Index (SAVI) were all derived from Landsat 8 Operational Land Imager (OLI)/Thermal Infrared Sensor (TIRS) that was downloaded with help of raster calculator on ArcGIS software.

Landsat $8, \mathrm{NDVI}=($ Band $5-$ Band 4$) /($ Band $5+$ Band 4$)$;

Landsat 8, SAVI $=(($ Band $5-$ Band 4$) /($ Band $5+$ Band $4+0.5)) \times(1.5)$.

Band 4 is red while Band 5 is NIR 


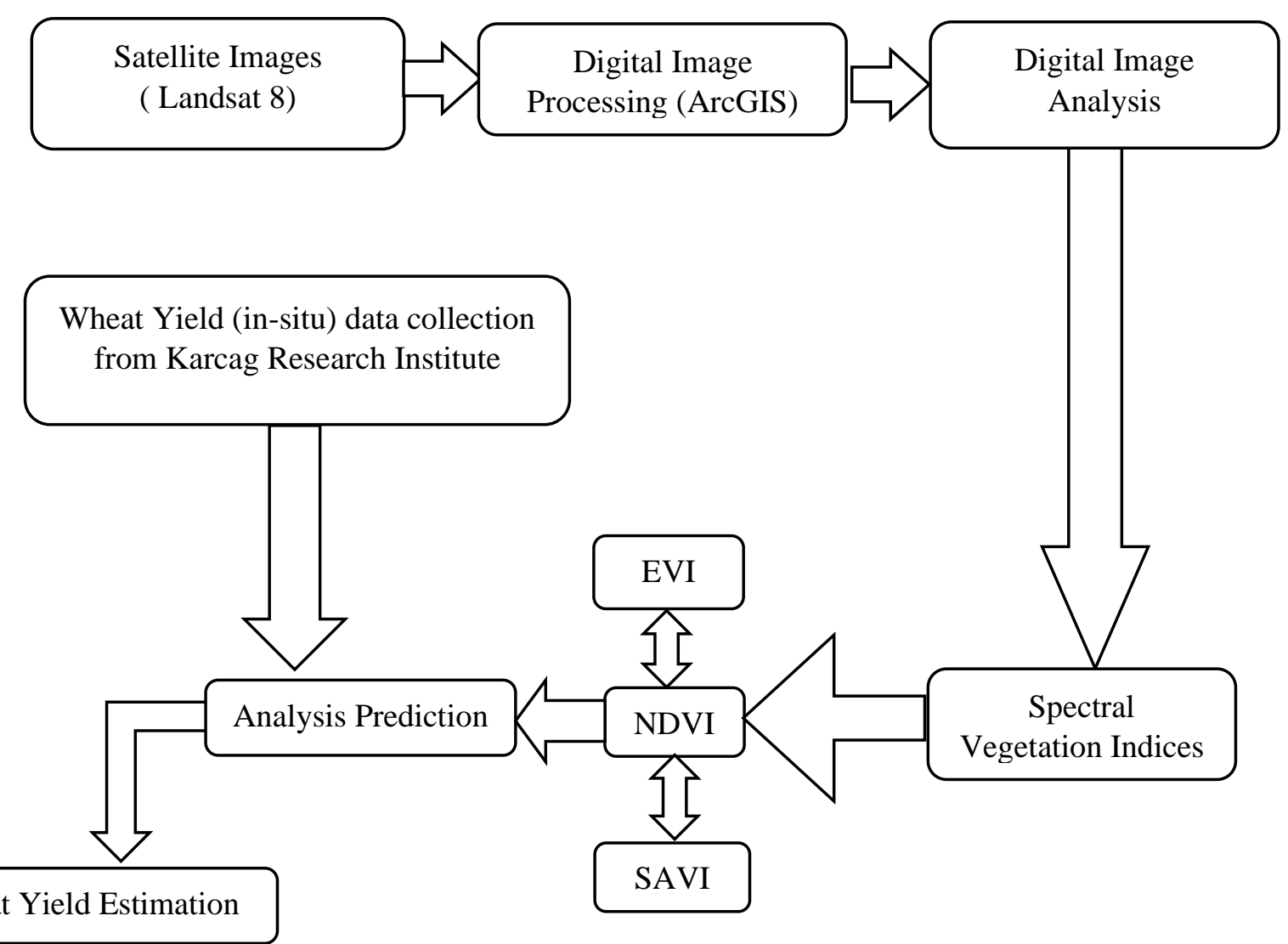

Figure 1. Flow chart of remote wheat yield estimation

\subsection{Statistical analysis}

The effect of independent variables (vegetation indices) on the dependent variable (wheat yield) was described by Linear regression model which was computed on Microsoft Excel sheet. This model was developed between the satellite derived spectral vegetation indices and the ground truthing yield data of the wheat crop in the study site. The performance of the model was verified by comparing the differences in coefficient of determination $\left(\mathrm{R}^{2}\right)$ and Root Mean Square Error (RMSE) in prediction. The accuracy of the model for prediction is better when the $\mathrm{R}^{2}$ is higher and the RMSE is lower. The $\mathrm{R}^{2}$ and the RMSE was calculated using the equations 4 and 5

$$
\begin{aligned}
& R^{2}=1-\frac{\sum_{i=1}^{n}\left(y_{i}-\dot{y}_{l}\right)^{2}}{\sum_{i=1}^{n}\left(y_{i}-\bar{y}\right)^{2}} \\
& R M S E=\sqrt{\frac{\sum_{i=1}^{n}\left(y_{i}-\dot{y}_{l}\right)^{2}}{n}}
\end{aligned}
$$

Equation 1

Equation 2 
Where: $y_{i}$ is predicted yield data; $y_{1}$ is the ground truthing yield data; $\bar{y}$ is the average yield; $n$ is the number of samples used for validation.

Also Normalized Root Mean Square Error (NRMSE) which is useful for comparing between predicted yield and ground truthing yield data and for comparing between seasons in case of variable yield ranges is calculated as Equation 6:

$$
N R M S E=\frac{\sqrt{\frac{\sum_{i=1}^{n}\left(y_{i}-y_{l}\right)^{2}}{n}}}{(\bar{y})}
$$

Equation 3

Another criterion used to assess the accuracy of the predictions of the wheat yield is NashSutcliffe efficiency ' $E_{1}$ '. Nash and Sutcliffe (1970) defined the efficency $E_{1}$ as one minus the sum of the absolute squared differences between the predicted yield and the ground truthing yield data normalized by the variance of the ground truthing yield data during the period under investigation. This is calculated as Equation 7:

$$
E_{1}=1-\frac{\sum_{i=1}^{n}\left(O_{i}-P_{i}\right)^{2}}{\sum_{i=1}^{n}\left(O_{i}-\bar{O}\right)^{2}}
$$

Equation 4

Where, $\mathrm{O}_{\mathrm{i}}$ is the observed value or ground truthing yield data, $\mathrm{P}_{\mathrm{i}}$ is the predicted yield values; $\overline{\mathrm{O}}$ is the mean/ average observed values. Values of $\mathrm{E}$ ranges between 1.0 (which is perfect fit) and $-\infty$. Here, an efficiency that is lower than zero indicates that the average value of the observed yield would have been a better predictor than the model.

\section{Results}

All these vegetation indices for each month with the field yield data were used to calculate equations for predicting wheat yield using simple regression analysis (Fig 2.). The growth of wheat leaves could experience several stages. These stages are the germination period, then the tillering period. The stem elongation began around March, and the heading/flowering stage begin, then ripening follows and the harvest is done in August. The curve of all indices showed higher values in the month of May and June compared with other months. This explained that the crop responds well during the spring time when there is enough rainfall. According to Viña Andrés et al., (2011), lower values of all vegetation indices proves that wheat crop might be at early stage or ground cover wasn't fully cover by the wheat crop. In August, wheat crop was harvested in this site. 


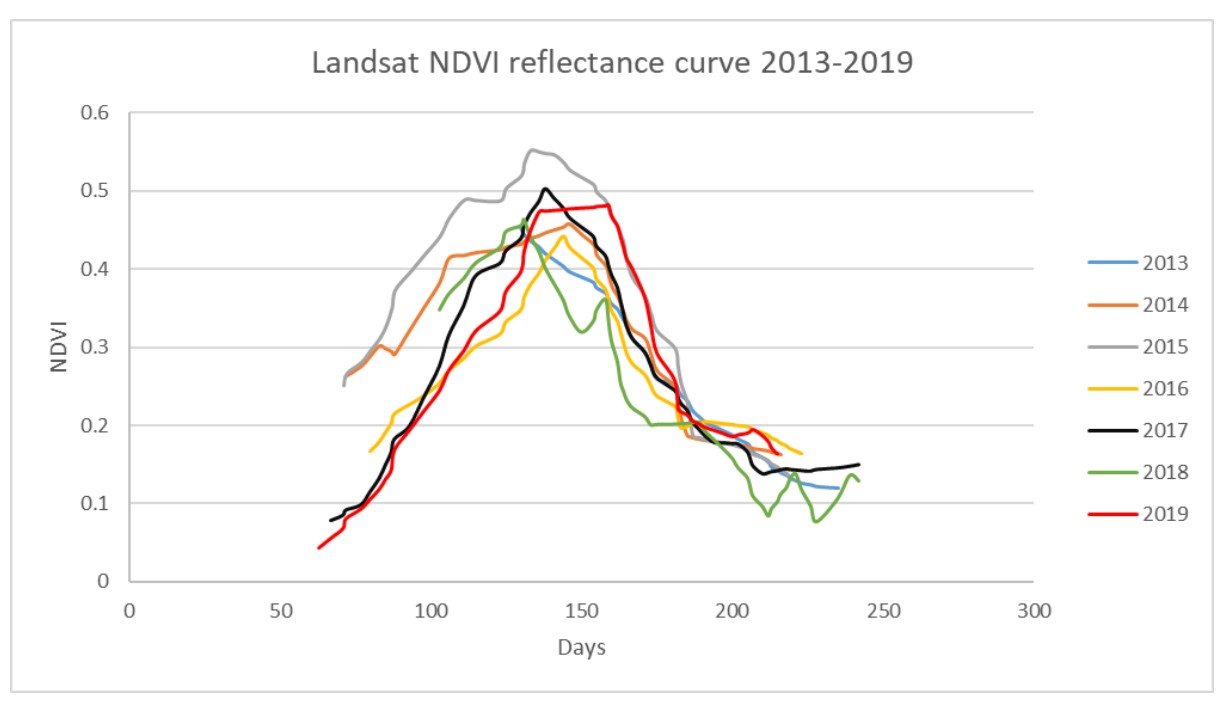

Figure 2: Landsat NDVI during the growing season of 2013 to 2019

The vegetation indices were noted to decline has the leaves age during the development of the fruit period (from June to July). According to Fig 2. the highest NDVI values was observed in the between 100th and 150th day of the year. The Landsat data NDVI value of the study site ranged from 0.04 to 0.55 .

\subsection{NDVI}

For each vegetation indices, the correlation between the vegetation indices and the yields almost look the same. The NDVI data on day 150,154, 160 and 163 of the year shows the strongest relationship with the average observed yield $\left(R^{2}=0.538, R^{2}=0.562, R^{2}=0.569\right.$ and $\mathrm{R}^{2}=0.522$ respectively)

Figure 3. shows the $\mathrm{R}^{2}$ values (coefficient of deterministic) peaked on the 160th day of the year which is during the beginning of ripening. The modelling time was consistent with the best time determined through their correlations. 


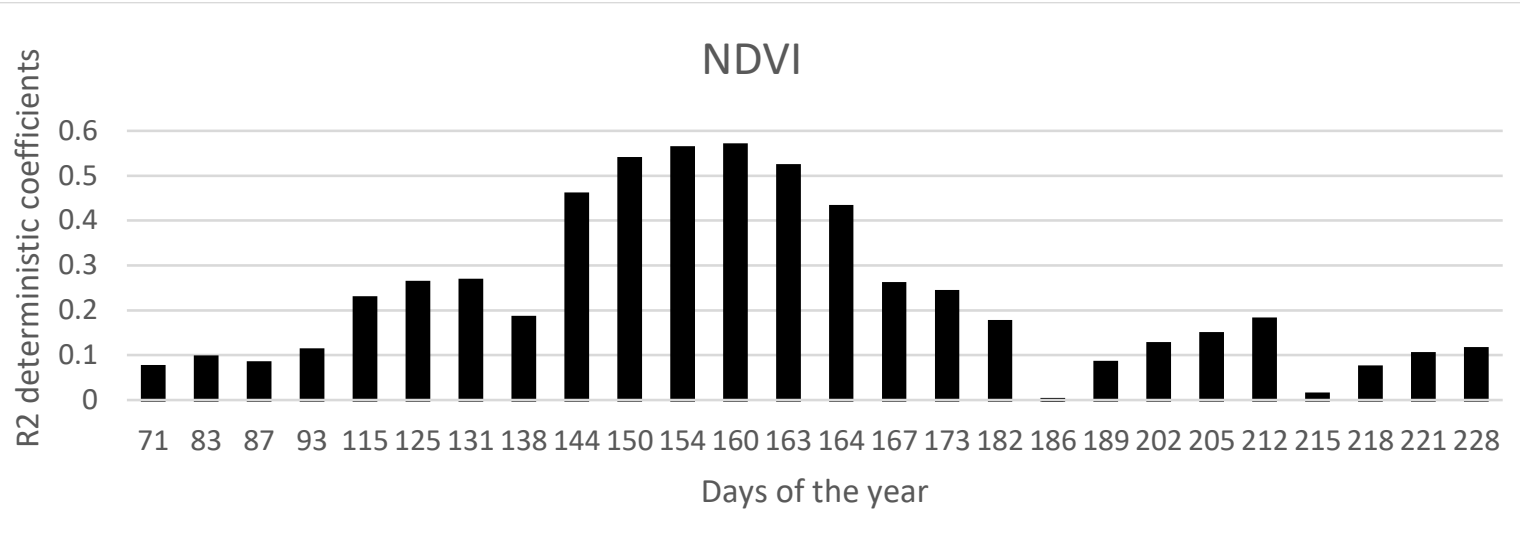

Figure 3. the deterministic coefficient $\left(\mathrm{R}^{2}\right)$ of NDVI across the days of the Year

According to literatures, remote sensing time series of at least 6 years should be used for analyzing crop yield (Dempewolf et al., 2014; Nagy et al., 2018). Regression models were developed over this site for six years (2013 to 2018). VI's with higher correlation were used respectively to establish regression models. The relationship between Landsat-NDVI and wheat yield were best described by linear function, accordingly, with the strongest correlation and highest accuracy (Fig.4). The deterministic coefficient of prediction models derived based on Landsat NDVI in different dates was varied during the vegetation period, and showed the highest value, $\mathrm{R}^{2}=0.569$ in the $160^{\text {th }}$ day. This mean that wheat in maximum biomass is the best time to make yield prediction.

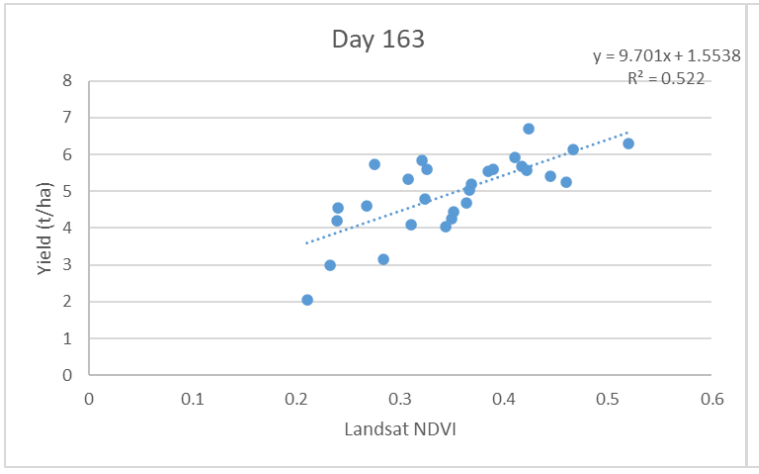

(a)

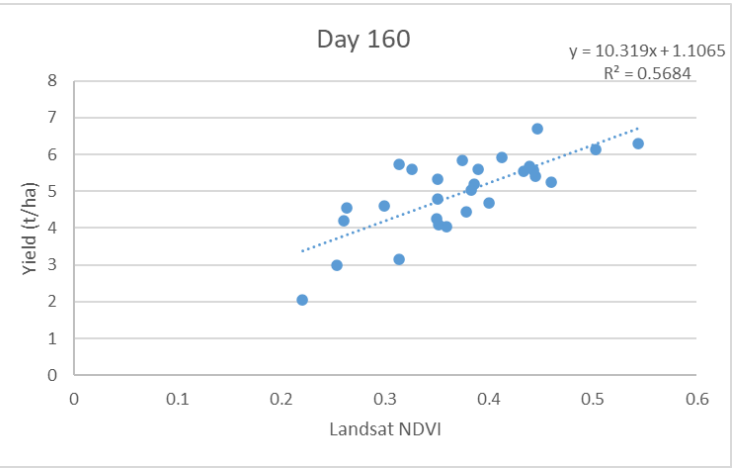

(b) 


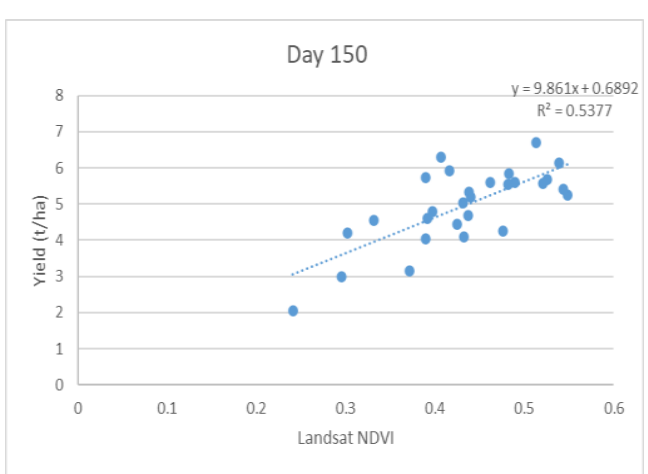

(c)

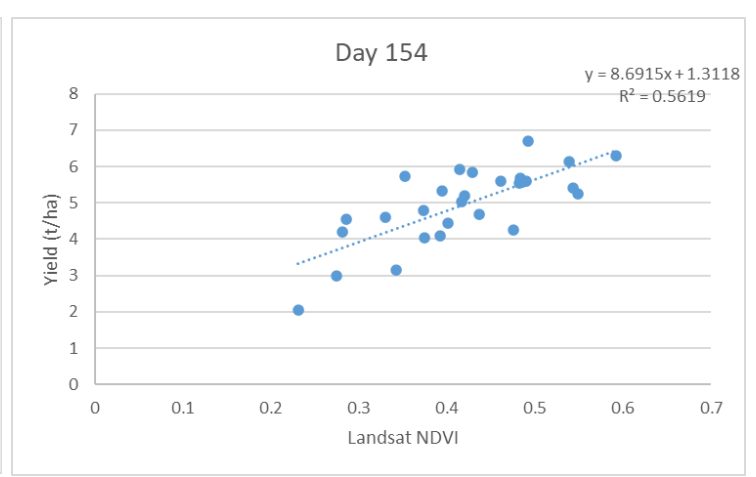

(d)

Figure 4 (a-d) Relationship between the NDVI and wheat yield

The ground truthing average wheat yield for the study area from 2018 to 2019 were used to further validate the ability of the proposed model. The average wheat NDVI of the $160^{\text {th }}$ day of the year for different region of the sites was ranging from 0.2531 to 0.5439 throughout the years. Figure 5. shows the histogram of the predicted yield and actual yields for all the regions.

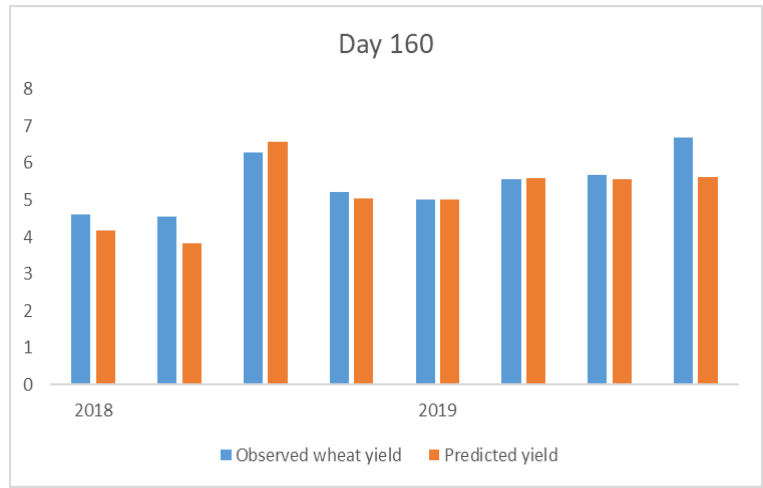

(a)

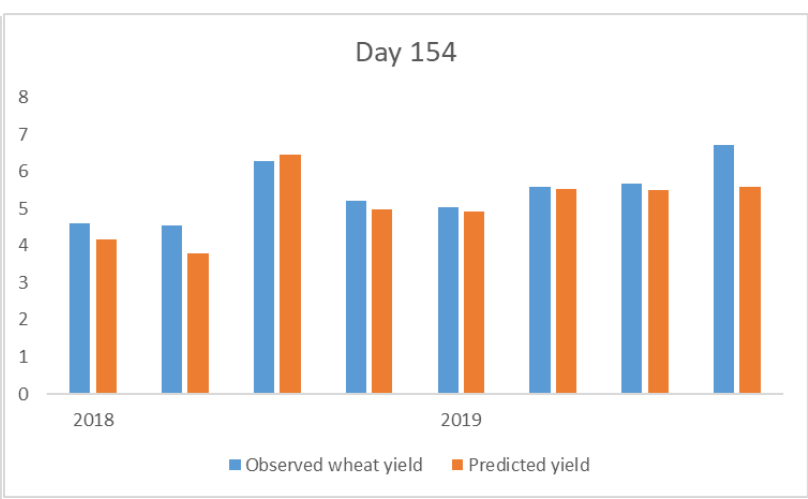

(b)

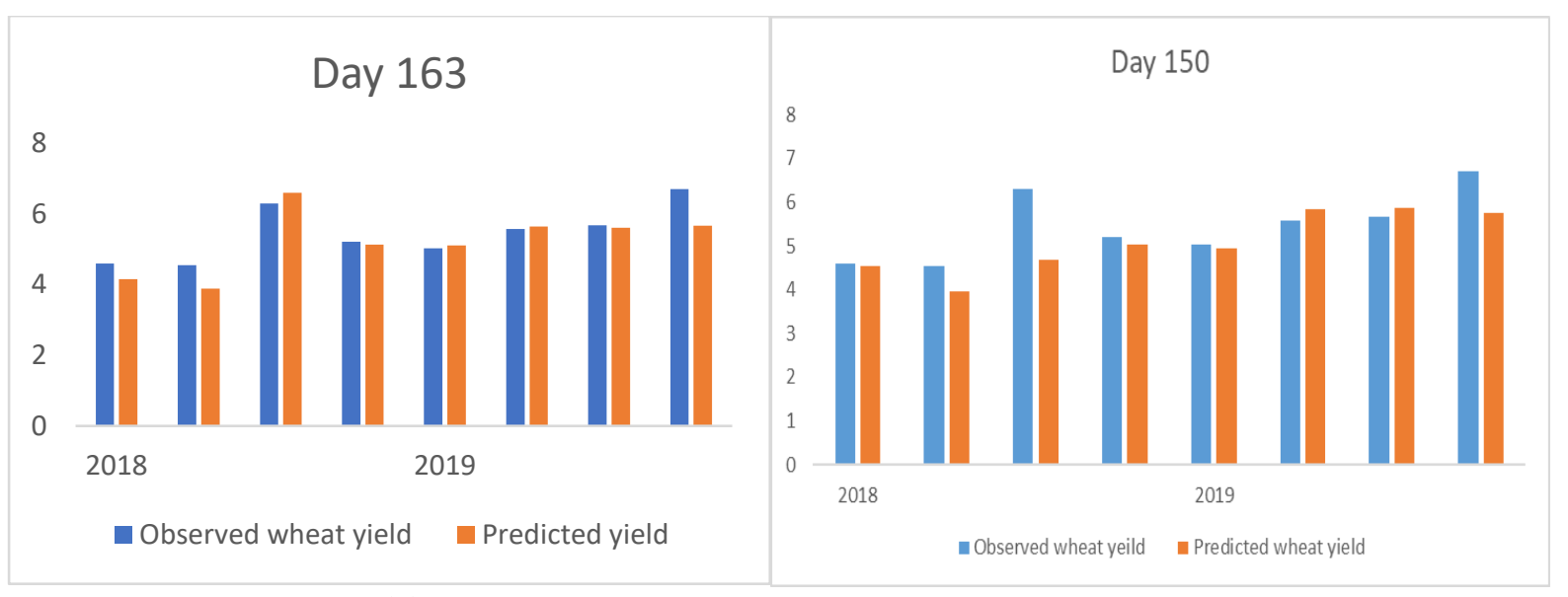

(c)

Figure 5 (a-c). histogram of Actual yield and Landsat NDVI predicted yield (t/ha) 
The performance and the validation of the models created from 6 years vegetation indices for wheat yield forecasting was validated using these 2018-2019 two years data. The results derived were compared to the ground truthing yield for each year. RMSE and the relative deviation (difference in percent) of forecast versus reported yield were calculated (Table 1).

Table 1 Yield validation and prediction models from 2018 to 2019

\begin{tabular}{lllll}
\hline Day & Equation & Year & RMSE (t/ha) & NRMSE (\%) \\
\hline \multirow{2}{*}{ 150th } & $y=9.861 \times N D V I_{d 150}+0.6892$ & 2018 & 0.854 & 16.56 \\
\cline { 3 - 5 } & & 2019 & 0.504 & 8.78 \\
\hline 154th & $y=8.6915 \times N D V I_{d 154}+1.3118$ & 2018 & 0.451 & 8.75 \\
\cline { 3 - 5 } & & 2019 & 0.562 & 9.78 \\
\hline \multirow{2}{*}{ 160th } & $y=10.319 \times N D V I_{d 160}+1.1065$ & 2018 & 0.440 & 8.53 \\
\cline { 3 - 5 } & & 2019 & 0.535 & 9.33 \\
\hline \multirow{2}{*}{ 163th } & $y=9.701 \times N D V I_{d 163}+1.5538$ & 2018 & 0.425 & 7.36 \\
\cline { 3 - 5 } & & 2019 & 0.522 & 10.39 \\
\hline
\end{tabular}

Table 1 shows the details of the equations and validated results of 2018-2019. The predicted error for day 150 and 154 decreases each year by year with a NRMSE (the \% of root means square error to average yield). 


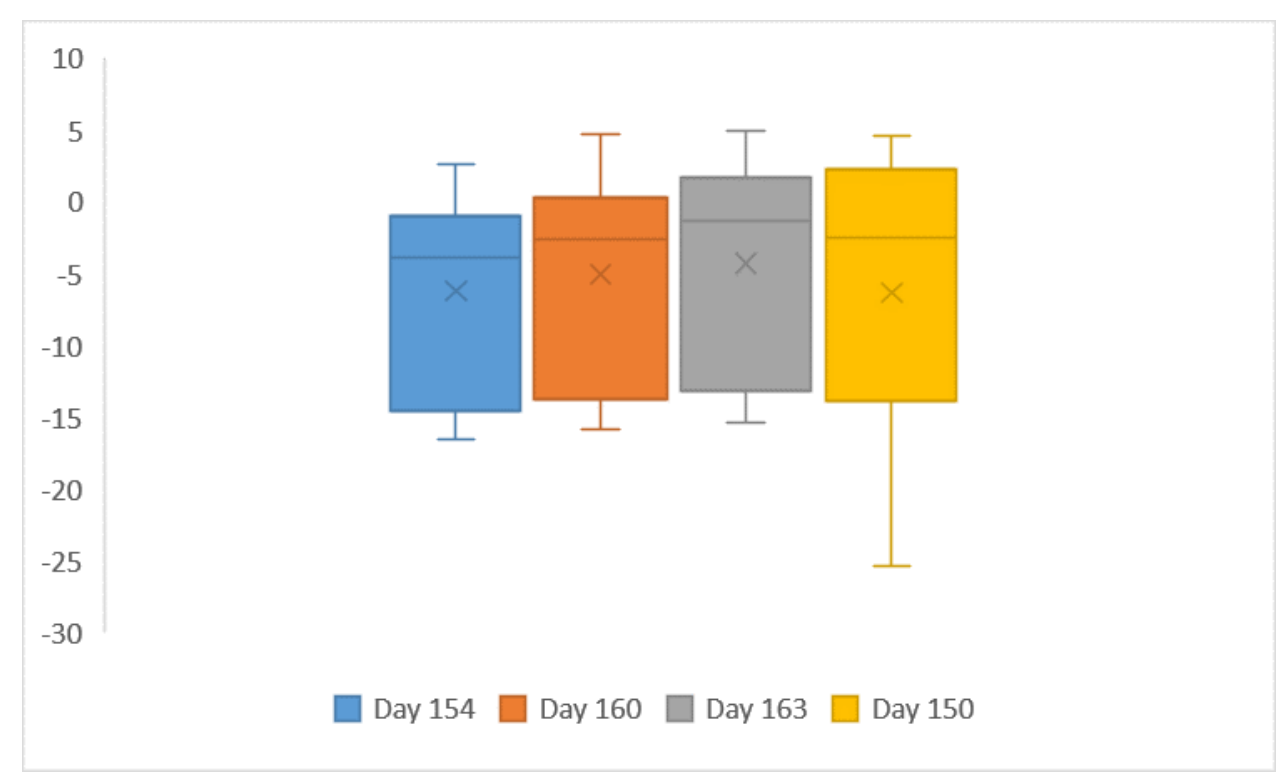

Figure (6) Relative deviation of the predicted yield from actual yield

Figure 6 shows the relative deviation of the predicted yield and the actual yield for Day 150, 154,160 and 163 , which are, $-6.31 \%,-6.20 \%,-5.05 \%$ and $-4.29 \%$ respectively. These negative average values connote that the result of the model is almost identical but lowly estimated the yield values on average

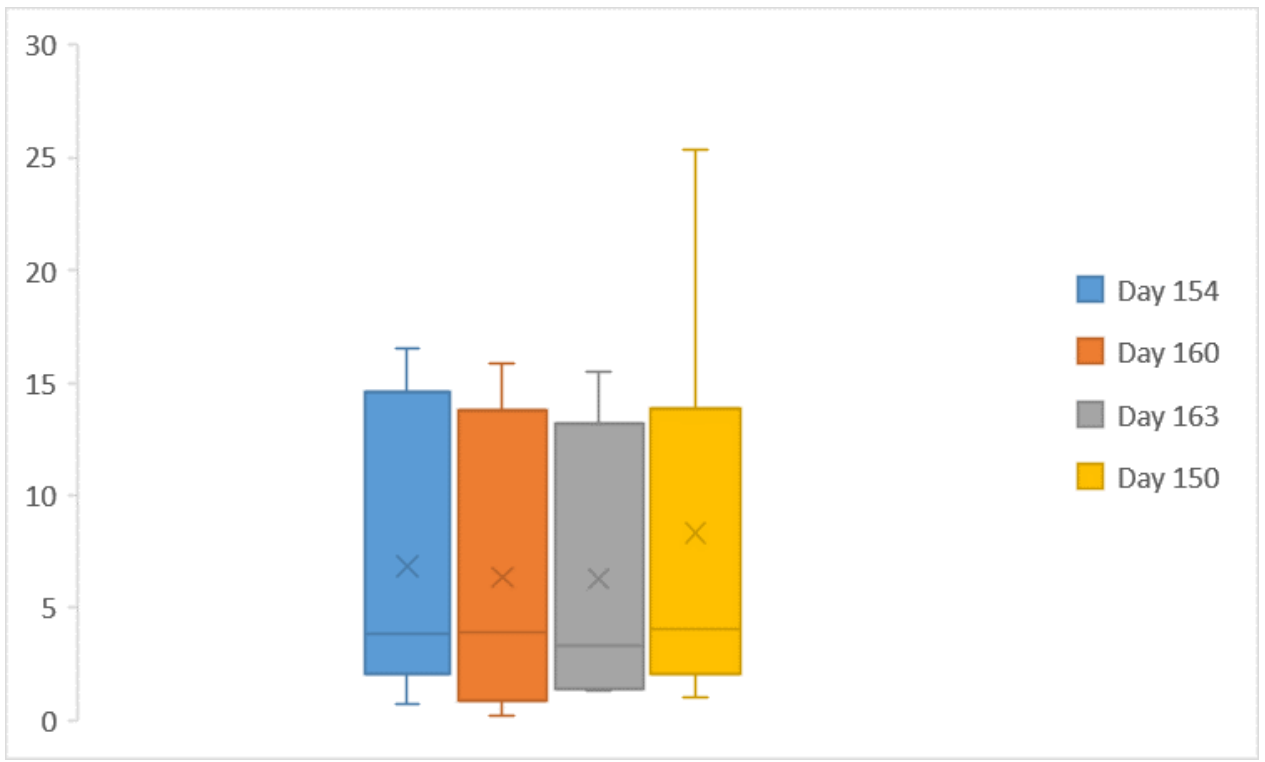

Figure (7) Absolute deviation of the predicted yield from actual yield

Figure 7 shows the Average absolute deviations between estimated and actual yield for Day $150,154,160$ and 163 , which are, $8.31 \%, 6.86 \%, 6.36 \%$ and $6.27 \%$ respectively. These values 
were not much but higher than the 5\% threshold that was generally accepted as good value (Ferencz et al., 2004).

\subsection{SAVI}

The SAVI data on day 158, 159 and 160 of the year shows the strongest relationship with the average observed yield $\left(R^{2}=0.500, R^{2}=0.521\right.$ and $R^{2}=0.534$ respectively). Figure 8 . shows the $\mathrm{R}^{2}$ values (coefficient of deterministic) peaked on the 160th day of the year which is during the beginning of ripening.

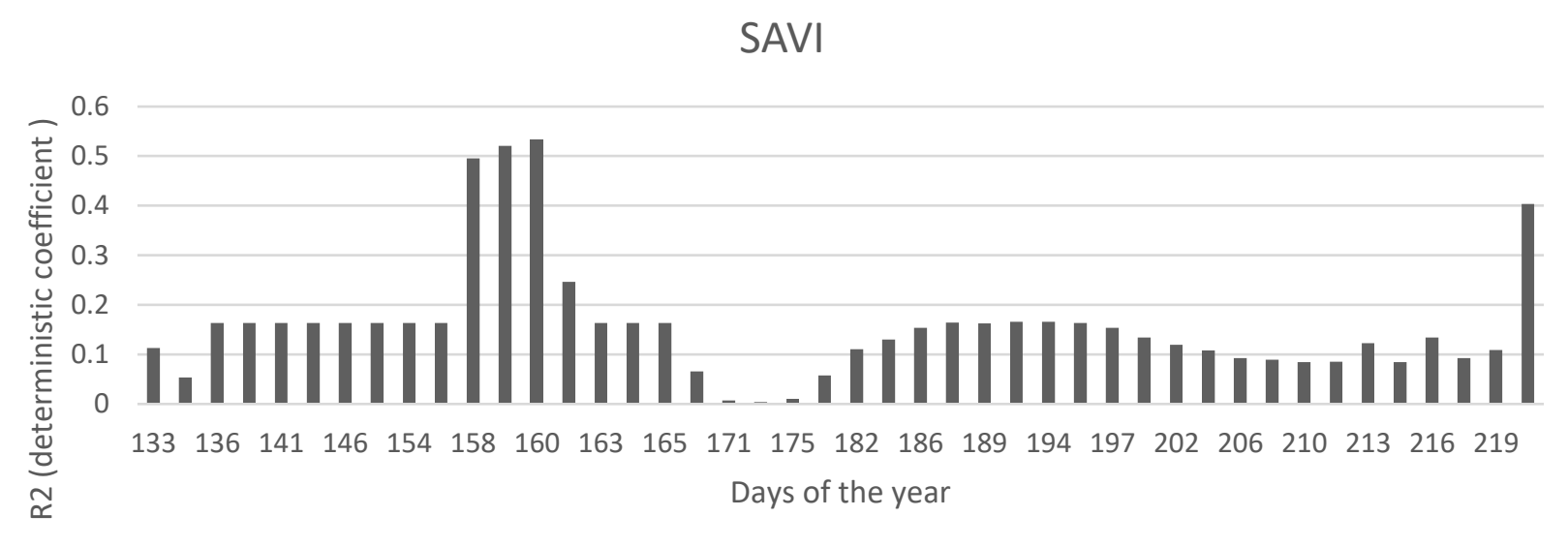

Figure 8. the deterministic coefficient $\left(\mathrm{R}^{2}\right)$ of NDVI across the days of the Year

Regression models were developed over this site for six years (2013 to 2018). SAVI with higher correlation were used respectively to establish regression models

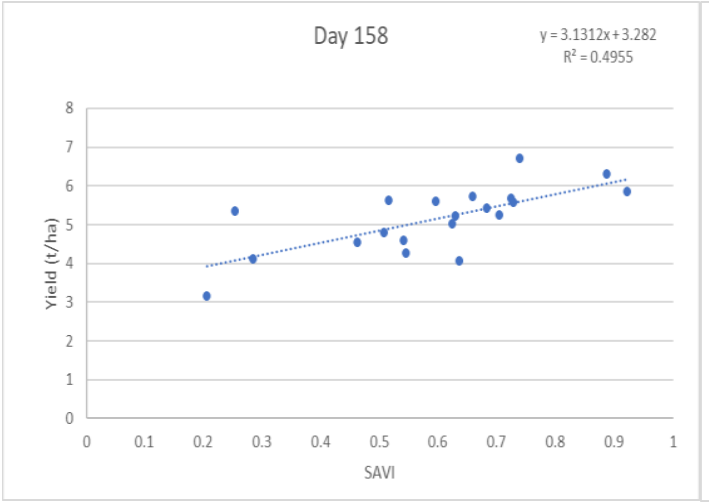

(a)

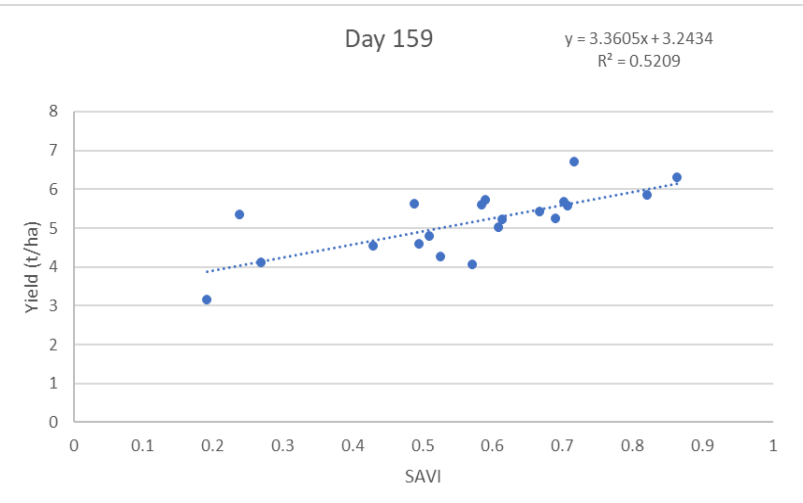

(b) 


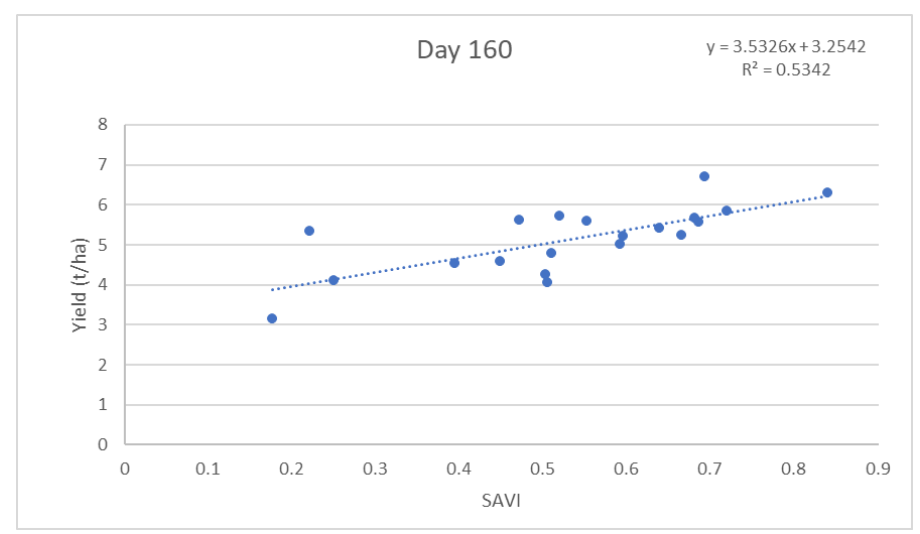

(c)

Figure 9(a-c) Relationship between the SAVI and wheat yield

The ground truthing average wheat yield for the study area from 2018 to 2019 were used to further validate the ability of the proposed model. Figure 10. shows the histogram of the predicted yield and actual yields for all the regions.

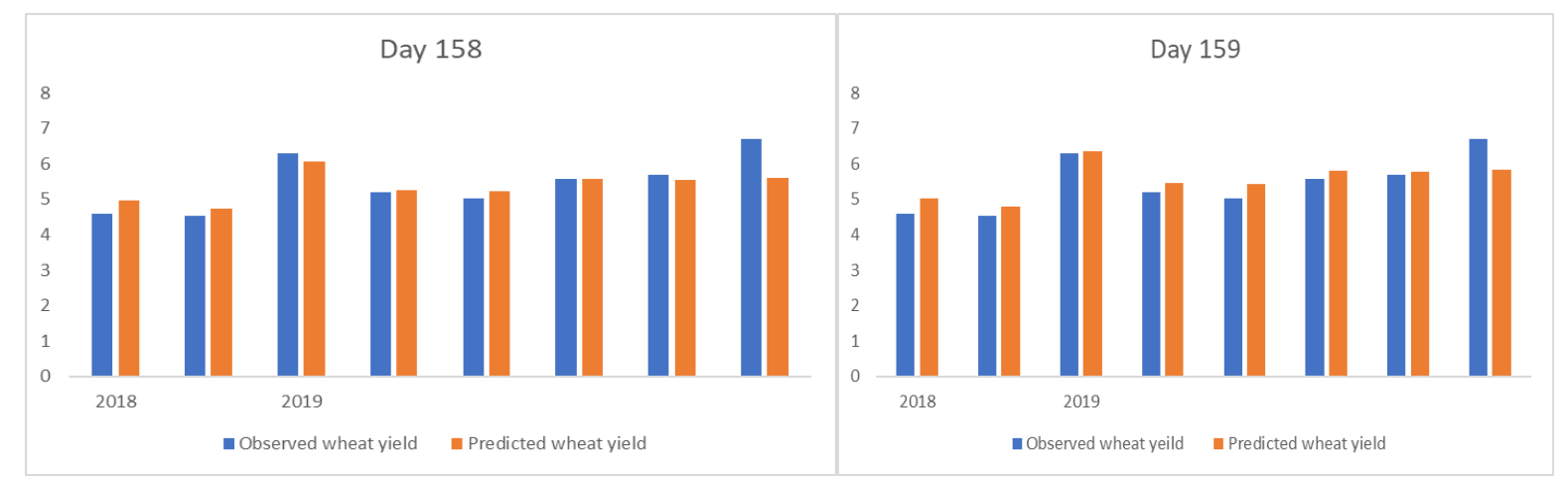

(a)

(b)

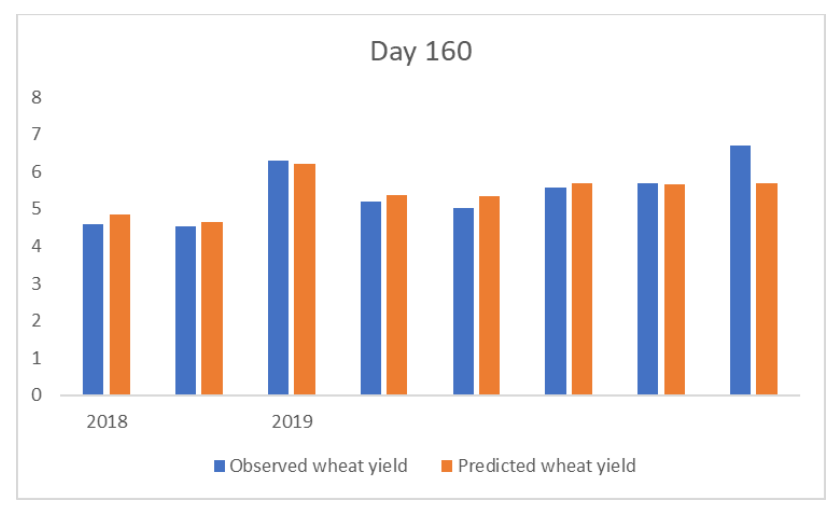

(c)

Figure 10. (a-c). histogram of Actual yield and Landsat SAVI predicted yield (t/ha) 
The performance and the validation of the models created from 6 years vegetation indices for wheat yield forecasting was validated using these 2018-2019 two years data. The results derived were compared to the ground truthing yield for each year. RMSE and the relative deviation (difference in percent) of forecast versus reported yield were calculated (Table 2).

Table 2 Yield validation and prediction models from 2018 to 2019

\begin{tabular}{lllll}
\hline Day & Equation & Year & RMSE (t/ha) & NRMSE (\%) \\
\hline \multirow{2}{*}{ 158th } & $y=3.1312 \times S A V I_{d 158}+3.282$ & 2018 & 0.301 & 6.59 \\
\cline { 3 - 5 } & & 2019 & 0.471 & 8.21 \\
\hline 159th & \multirow{2}{*}{$y=3.3605 \times S A V I_{d 159}+3.2434$} & 2018 & 0.584 & 8.75 \\
\cline { 3 - 5 } & & 2019 & 0.562 & 9.78 \\
\hline \multirow{2}{*}{ 160th } & $y=3.5326 \times S A V I_{d 160}+3.2542$ & 2018 & 0.188 & 4.11 \\
\cline { 3 - 5 } & & 2019 & 0.435 & 7.57
\end{tabular}

Table 2 shows the details of the equations and validated results of 2018-2019. The predicted error increases each year by year with a NRMSE (the \% of root means square error to average yield).

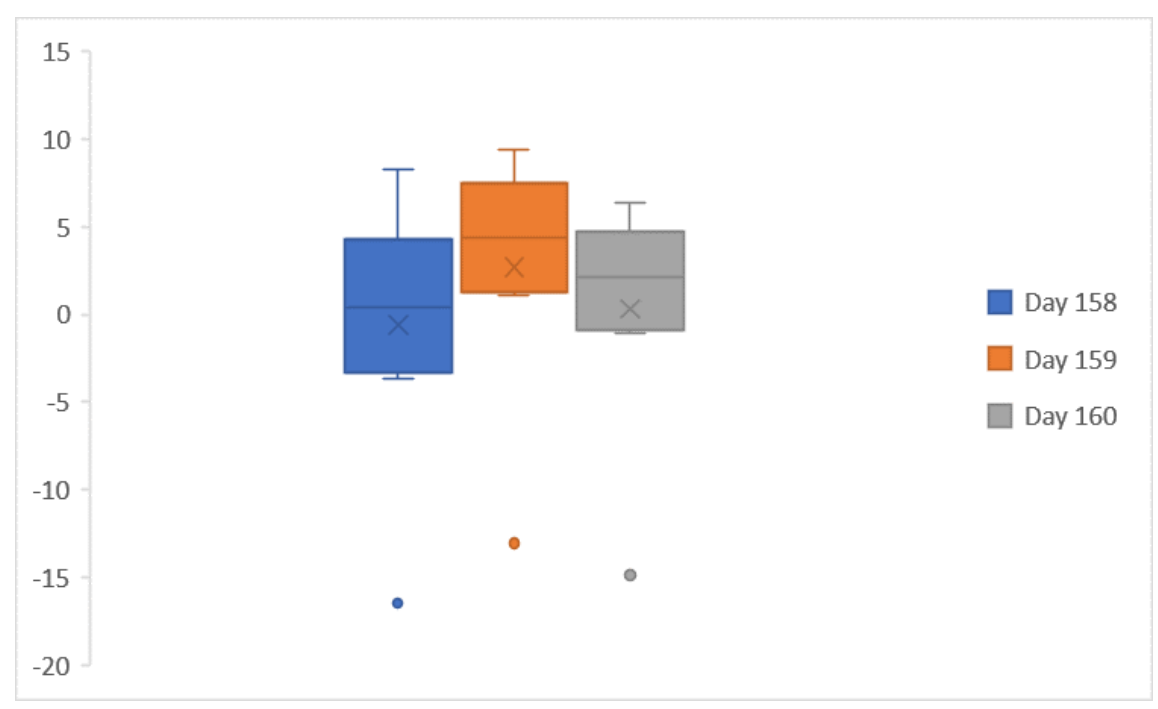

Figure 11. Relative deviation of the predicted yield from actual yield 


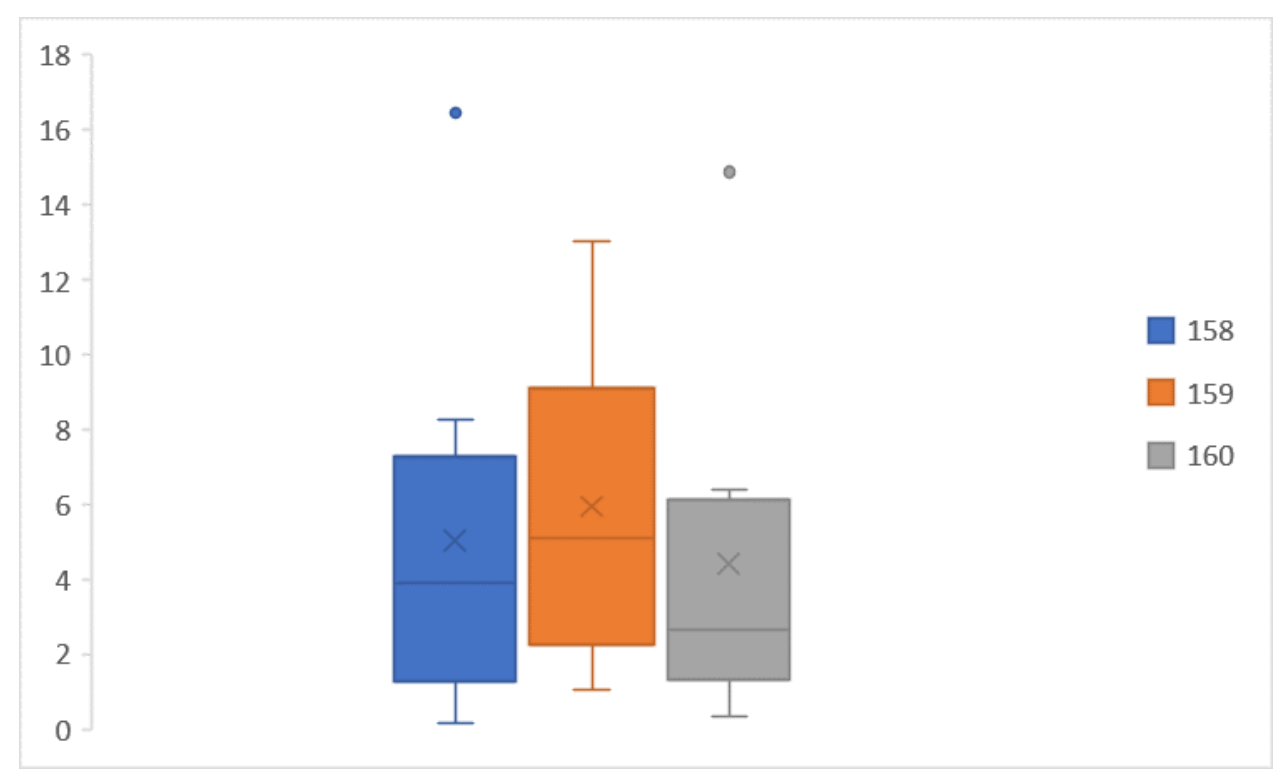

Figure 12. Absolute deviation of the predicted yield from actual yield

Figure 11. shows the relative deviation of the predicted yield and the actual yield for Day 158, 159 and 160 , which are, $-0.60 \%, 2.69 \%$ and $0.32 \%$ respectively. These negative average values connote that the result of the model is almost identical but lowly estimated the yield values on average. Figure 12. shows the Average absolute deviations between estimated and actual yield for Day 158, 159 and 160, which are, 5.03\%, 6.00\% and 4.41\% respectively. These values were not much but higher than the $5 \%$ threshold that was generally accepted as good value (Ferencz et al., 2004).

But the performance of the Landsat NDVI and SAVI wheat yield forecast was also tested using the Nash-Sutcliffe efficiency index, $\left(\mathrm{E}_{1}\right)$, which is a global measure of model efficiency. The Nash-Sutcliffe efficiency index is positive with $\mathrm{E}_{1}=0.57$ in the NDVI wheat forecast and that of SAVI is $\mathrm{E} 1=0.99$.

\section{Discussion}

In this study, the Landsat derived vegetation indices during the flowering stage of the wheat development was found to be siginificantly correlated to the wheat yield in all study site. In agreement with previous studies, the current study has demostrated correlations between the VIs during the flowering/fruiting spike period and crop yields (Marti et al., 2007, Labus et al., 2002, Mkhabela et al., 2011, Tiecheng et al., 2019), which has been admited as the most critical period for most crops yield forecasting, however, SAVI demostrated higher correlations during the flowering/fruiting spike period and crop yield. This also is in agreement with Liaqat et al., (2017) study on evaluating MODIS and Landsat multiband vegetation indices for wheat yield, 
of which SAVI derived from Landsat image demonstrated maximum correlation than NDVI and EVI. In addition to this, the greenest period of the crop were defined by referring to the highest NDVI value were used to predict the crop yield (Yousfi et al., 2016), of which it is usually during the fruiting spike of the wheat plant period. Moreover, the results in this study has shown that NDVI and SAVI during the main fruiting spike period $\left(160^{\text {th }}\right.$ day of the year) do have an higher accuracy for wheat yield prediction which is in accordance to Tiecheng et al. (2019) studies on Jujube yield predition. However, the higher value of SAVI connote that it takes into accounts the soil background which is neglected in NDVI and this gives a good agreement with wheat yield ground truthing data. Hence, model derived from SAVI is considered to be better than NDVI.

For crop yield prediction, MODIS data is more suitable at large regional scales. But because of the coarser pixels of the reflectance data from MODIS, a higher scale errors is usually resulted (Huang et al., 2015). However, Landsat or any other satellites that has higher spatial resolution do provides better precision fragmented vegetation index for predicting yield at regional scales (Bolton and Friedl, 2013), of which it has been achieved in predicting the yield of wheat in this study. In agreement with other studies, this study has shown the validty of using satellite derived vegetation indices for predicting wheat yield. The result after validation shows a fairly good agreement between the wheat yield derived from Landsat derived SAVI and ground truthing yield; with an average absolute deviation between the predicted yield and observed yield was $4.22 \%$ while that of NDVI was $6.47 \%$, of which the SAVI is less than the $5 \%$ threshold that was generally accepted as good value (Ferencz et al., 2004), better than some other results. For instance, the final reported values in Pakistan with MODIS NDVI was 10\% (Dempewolf et al., 2014) which is higher than this study's result. Also, studies by Rudorff and Batista (1991) estimated wheat yield at the farm level using Landsat in the Brazil with a standard error/predicted error of 0.37-0.44 t/ha. The wheat and maize yield forcasting for the Tisza river catchment using MODIS NDVI was 7\% difference between the predicted and actual yield (Nagy et al., 2018), this study performs better than all these result. In this study, NDVI and SAVI derived from Landsat 8 was seen to be well correlated with wheat yield with NashSutcliffe efficiency index being positive with $\mathrm{E}_{1}=0.99$ for the model from SAVI and for NDVI, $\mathrm{E}_{1}=0.57$, which connote that the forecasting method developed and evaluated performs acceptable forecast efficiency. It can be accepeted that moderate and high spatial resolution remote sensing images such as Landsat 8 images have the potential for predict wheat yield even 
at a regional scale like this study area and much more in a small farm because of its spatial resolution.

\section{Conclusion}

This study has shown that vegetation indices derived from Landsat 8 time series data images can be used to predict winter wheat yield for this study site. This study was based on high spatial resolution data (Landsat-VIs) and ground truthing data of winter wheat which are grown in Karcag and other nearby settlements. The result of this study has shown that the beginning of ripening period was the best time to predict winter wheat yields. The NDVI and SAVI of $160^{\text {th }}$ day of the year was verified to best fit for wheat yield prediction with the highest $\mathrm{R}^{2}$. In addition to this, the relationship between vegetation indices derived from Landsat (NDVI and SAVI) and wheat yield was well described by a linear regression model. This proposed model showed a better performance for wheat yield prediction with SAVI model based performing better than NDVI model based. Hence, model derived from SAVI is considered to be better than NDVI. This development of wheat yield forecast will provide timely information on wheat production, status and yield in a well standard and regular pattern from this region to the international catchment level.

Aside the accuracy of the yield prediction, another essential component in forecasting is the understanding of the applicability of the prediction because the main goal is to minimize forecast uncertainties for a particular location and for an agricultural or economical sector. With this prediction method, good estimation is provided on time during the growing season of the crops and this can be updated periodically as the season goes until harvest. Timely information like this to the farmers or decision makers will minimize the impacts of possible losses of crop yield and appropriate mitigation measures and readiness by putting some plans in place. This information will also help stakeholders to take early decisions and locate geographically, areas that has large variation in productivity of which is most vital necessity for food security and trade.

\section{Acknowledgment}

The research was financed by the Higher Education Institutional Excellence Programme (NKFIH-1150-6/2019) of the Ministry of Innovation and Technology in Hungary, within the framework of the 4th thematic programme of the University of Debrecen. 
Reference

Bognára Péter, Anikó Kerna, Szilárd Pásztora, János Lichtenbergerb, Dávid Koronczaya, and Csaba Ferencza. (2017, March 21). Yield estimation and forecasting for winter wheat in Hungary using time series of MODIS data. International Journal of Remote Sensing, 38(11), 3394-3414. doi:https://doi.org/10.1080/01431161.2017.1295482

Bolton Douglas K. and Friedl Mark A. (2013, May). Forecasting crop yield using remotely sensed vegetation indices and crop phenology metrics. Agricultural and Forest Meteorology, 173(15), pp. 74-84. doi:https://doi.org/10.1016/j.agrformet.2013.01.007

Cai X.L. and Sharma B.R.,. (2010). Integrating remote sensing, census and weather data for an assessment of rice yield, water consumption and water productivity in the IndoGangetic river basin. Agricultural Water Management, 97, 309-316.

Deering, D. (1978). Rangeland Reflectance Characteristics Measured by Aircraft and Spacecraft Sensors. Retrieved from https://ci.nii.ac.jp/naid/10007236109/

Dempewolf Jan, Adusei Bernard, Becker-Rehef Inbal, Hansen Matthew, Potapov Peter, Khan Ahmad and Barker Brian. (2014). Wheat Yield Forecasting for Punjab Province from Vegetation Index Time Series and Historic Crop Statistics. Remote Sensing, 6(10), pp. 9653-9675. doi:https://doi.org/10.3390/rs6109653

Ferencz Cs., P. Bognár, J. Lichtenberge, D. Hamar, Tarcsai Gy, G. Timár, G. Molnár, Sz Pásztor, P. Steinbach, B. Székely, O.E. Ferencz, I. Ferencz-Árkos. (2004). Crop yield estimation by satellite remote sensing. International Journal of Remote Sensing, 25(20), 4113-4149. doi:https://doi.org/10.1080/01431160410001698870

Fu, Y., Yang, G., Wang, J., Song, X., Feng, H. (2014). Winter wheat biomass estimation based on spectral indices, band depth analysis and partial least sqaures regression using hyperspectral measurements. Computer Electronic Agriculture, 100, 51-59.

Groten, S. (1993). NDVI-crop monitoring and early yield assessment of Burkina Faso. International Journal of Remote Sensing, 14, 1495-1515.

Huang J., Tian L., Liang S., Ma H., Becker-Reshef I., Huang Y., Su W., Zhang X., Zhu D., Wu W. (2015, May 15). Improving winter wheat yield estimation by assimilation of the leaf area index from Landsat TM and MODIS data into the WOFOST model. Agricultural and Forest Meteorology, 204, 106-121. doi:https://doi.org/10.1016/j.agrformet.2015.02.001

Labus M.P., Nielsen G.A., Lawrence R.L., Engel R., Long D.S. (2002). Wheat yield estimates using multi-temporal NDVI satellite imagery. International Journal of Remote sensing, 23(20), 4169-4180. doi:https://doi.org/10.1080/01431160110107653

Liaqat Usman Muhammad, Cheema Masud Jehanzeb Muhammad, Huang Wenjiang, Mahmood Talha, Zaman Muhammad, Khan Mohsin Muhammad. (2017). Evaluation of MODIS and Landsat multiband vegetation indices used for wheat yield estimation in irrigated. Computers and Electronics in Agriculture, 138, 39-47. 
Liu L., J. Wang, Y. Bao, W. Huang, Z. Ma, C. Zhao. (2006). Predicting winter wheat condition, grain yield and protein content using multi-temporal EnviSat-ASAR and Landsat TM satellite images. International Journal of Remote Sensing, 27(4), pp. 737-753. doi:https://doi.org/10.1080/01431160500296867

Lyle Greg, Megan Lewis and Bertram Ostendorf. (2013). Testing the Temporal Ability of Landsat Imagery and Precision Agriculture Technology to Provide High Resolution Historical Estimates of Wheat Yield at the Farm Scale. Remote Sensing(5), 1549-1567. doi:10.3390/rs5041549

Malingreau, J.-P. (1986). Global vegetation dynamics: satellite observations over Asia. Remote Sensing of Environment, 7, 1121-1146.

Marti J., Bort J., Slafer G.A., Araus J.L. (2007). Can wheat yield be assessed by early measurements of Normalized Difference Vegetation Index? Annals of Applied Biology, 150, 253-257. doi:10.1111/j.1744-7348.2007.00126

Maselli F., Conese C., Petkov L., Gilabert M. A. (1992). Use of NOAA-AVHRR NDVI data for environmental monitoring and crop forecasting in the Sahel. Preliminary results. Remote Sensing of Environment, 13, 2743-2749.

Nagy Attila, János Fehér, János Tamás. (2018, August). Wheat and maize yield forecasting for the Tisza river catchment using MODIS NDVI time series and reported crop statistics. Computers and Electronics in Agriculture, 151. doi:10.1016/j.compag.2018.05.035

Nash J.E., Sutcliffe J.V. (1970). River flow forecasting through conceptual models, Part I - A discussion of principles. Journal of Hydrology, 10, 282-290.

Mkhabela M.K., Bullock P., Raj S., Wang S., Yang Y. (2011, March 15). Crop yield forecasting on the Canadian Prairies using MODIS NDVI data. Agricultural and Forest Meteorology, 151(3), 385-393. doi:https://doi.org/10.1016/j.agrformet.2010.11.012

Patel N.K., C. Patnaik, S. Dutta, A.M. Shekh, A.J. Dane. (2001). Study of crop growth parameters using Airborne Imaging Spectrometer data. International Journal of Remote Sensing, 22(12), 2401-2411. doi:https://doi.org/10.1080/01431160117383

Pena-Barragan, J.M., Ngugi, M.K., Plant, R.E., Six, J. (2011). Object-based crop identification using multiple vegetation indices, textuaral features and crop phenology. Remote Sensing of Environment, 115(6), 1301-1316.

Potgieter, A.B., Power, B., Mclean, J., Davis, P., Rodriguez, D. (2014, September). Spatial Estimation of Wheat Yields from Landsat's Visible, near Infrared and Thermal Reflectance Bands. International Journal of Remote Sensing Applications, 4(3). doi: 10.14355/ijrsa.2014.0403.03

Rasmussen, M. (1992). Assessment of millet yields and production in northern Burkina Faso using integrated NDVI from the AVHRR. Remote sensing of Environment, 13, 34313342.

Rembold F., Atzberger C., Rojas O., Savin I. (2013). Using low resolution satellite imagey for yield prediction and yield anomaly detection. Remote Sensing, 11(5), 1704-1733. doi:https://doi.org/10.3390/rs5041704 
Reynolds C.A., M. Yitayew, D.C. Slack, C.F. Hatchinson, A. Huete, M.S. Petersen. (2000). Estimating crop yields and production by integrating the FAO Crop Specific Water data and ground-based ancillary data. International Journal of Remote Sensing, 3487-3508.

Richter K., C. Atzberger, F. Vuolo, G. D’Urso. (2011, June). Evaluation of sentinel-2 spectral sampling for radiative transfer model based LAI estimation of wheat, sugar beet, and maize. IEEE Journal of Selected Topics in Applied Earth Observations and Remote Sensing, 4(2), 458-464.

Rudorff B.F.T, Batista G. T. (1991). Wheat yield estimation at the farm level using TM Landsat and agrometeorological data. International Journal of Remote Sensing, 12, 2477-2484. doi:10.1080/01431169108955281

Tiecheng Bai, Nannan Zhang, Benoit Mercatoris, Youqi Chen. (2019, July). Jujube yield prediction method combining Landsat 8 Vegetation Index and the phenological length. Computers and Electronics in Agriculture, 162, 1011-1027. doi:https://doi.org/10.1016/j.compag.2019.05.035

Tucker C.J, Vanpraet C.L, Sharman M.J., Van Ittersum G. (1985, June). Satellite remote sensing of total herbaceous biomass production in the Senegalese Sahel: 1980-1984. Remote sensing of Environment, 17(3), 233-249.

Tucker C.J., Holben B.N., Elgin J.H. Jr., McMutrey III. J.E. (1980). Relationship of spectral data to grain yield variation. Photogrammetric Engineering \& Remote Sensing, 46(5), pp. $657-666$

Tucker, C. (1979, May). Red and photographic infrared linear combinations for monitoring vegetation. Remote Sensing of Environment, 8(2), pp. 127-150. doi:https://doi.org/10.1016/0034-4257(79)90013-0

Viña Andrés, Anatoly A. Gitelson, Anthony L. Nguy-Robertson, Yi Peng. (2011). Comparison of different vegetation indices for the remote assessment of green leaf area index of crops. Remote Sensing of Environment.

Vuolo F., N. Neugebauer, S. Falanga, C. Atzberger, G. D’Urso. (2013). Estimation of Leaf Area Index using DEIMOS-1 data: calibration and transferability of a semi-empirical relationship between two agricultural areas. Remote Sensing, 5(3), 1274-1291. doi:https://doi.org/10.3390/rs5031274

Woodcock C.E., R. Allen, M. Anderson, A. Belward, R. Bindschadler, W. Cohen, F. Gao, S.N. Goward, D. Helder, E. Helmer, R. Nemani. (2008, May 23). Free access to Landsat imagery. Science, 1011. doi:10.1126/science.320.5879.1011a

World Wheat Production 2016. Retrieved November 11, 2017, from https://www.worldwheatproduction.com/

Wu, J., Wang, D., Bauer, M.E. (2007). Assessing broadband vegetation indices and QuickBird data in estimating leaf area index of corn and potato canopies. Field Crop Research, $102,33-42$. 
Xie, Q., Huang, W., Dash, J., Song, X., Huang, L., Zaho, J., Wang, R. (2015). Evaluating the potential of vegetation indices for winter wheat LAI estimation under different fertilization and Water conditions. Advanced Space Research, 56, 2365-2373.

Yousfi S., Kellas N., Saidi L., Benlakehal Z., Chaou L., Siad D., Herda F., Karrou M., Vergara O., Gracia A., et al. (2016). Comparative performance of remote sensing methods in assessing wheat performance under Mediterranean conditions. Agricultural Water Mangement, 164, 137-147. 